\title{
PROCENA MEHANIČKIH OSOBINA MIŠIĆA PRIMENOM BIOMEHANIČKE DIJAGNOSTIKE
}

\author{
Ivan Ćuk ${ }^{1 *}$, \\ Milena Živković ${ }^{2}$ \\ 'Univerzitet Singidunum, \\ Beograd, Srbija \\ ${ }^{2}$ Fakultet sporta i fizičkog vaspitanja, \\ Univerzitet u Beogradu, \\ Beograd, Srbija
}

\begin{abstract}
Rezime:
Sila, brzina i snaga predstavljaju najznačajnije mehaničke osobine mišića koje u velikoj meri određuju motoričke sposobnosti čoveka. Procena ovih osobina je od velikog značaja za sport, fizikalnu medicinu i rehabilitaciju jer se bez povratne informacije ne može uticati na njihove promene. Savremene metode biomehaničke dijagnostike nam mogu omogućiti preciznu i jednostavnu procenu osnovnih mehaničkih osobina mišića. Glavni cilj ove studije jeste analiza metoda biomehaničke dijagnostike koji se mogu koristiti u proceni mehaničkih osobina mišića. Dinamometrijska, tenziometrijska i kinematička metoda su najčešće korišćene metode biomehaničke dijagnostike koji se u sportu, ali i fizikalnoj medicini i rehabilitaciji koriste za procenu mehaničkih osobina mišića. Primena ovih metoda ne bi bila moguća bez odgovarajuće tehnologije. U tu svrhu, najčešće se koriste izokinetički dinamometri, tenziometrijske platforme i kamere za trodimenzionalnu kinematičku analizu pokreta. Navedene metode, odnosno prateće tehnologije, omogućuju određivanje kinetičkih (dinamičkih) i kinematičkih parametara kod jednozglobnih i višezglobnih pokreta. Rezultat toga ogleda se u poznavanju mehaničkih osobina mišića, čime se otvara mogućnost praćenja efekata treninga, terapije, utvrđivanje mišićnog disbalansa, praćenje razvoja motoričkih sposobnosti kod dece i utvrđivanje eventualnih motoričkih nedostataka. Zahvaljujući napretku biomehaničke dijagnostike stiče se preciznija slika o dizajnu i funkciji čovekovog lokomotornog aparata.
\end{abstract}

Ključne reči:

Maksimalna sila, brzina, snaga, tenziometrija, kinematika.

\section{UVOD}

Testiranje je sastavni deo sporta i medicinskih nauka kao što su kineziologija, fizikalna medicina, rehabilitacija i dr. Uloga testiranja ogleda se u povratnoj informaciji koja se pruža trenerima, sportistima, lekarima, fizioterapeutima i drugim stručnim licima. Dobijena informacija se dalje koristi u planiranju i formiranju određenih programa fizičkih aktivnosti u cilju ostvarivanja napretka i postizanja maksimalnih rezultata.

U praksi se koriste raznovrsni testovi kojim se procenjuju različita mehanička svojstva mišića. Pod mehaničkim svojstvima mišića podrazumevaju se one osobine mišića koje se mogu proceniti mehaničkim veličinama [1]. Sila, brzina i snaga predstavljaju osnovne i najznačajnije
Odgovorno lice:

Ivan Ćuk

e-pošta:

icuk@singidunum.ac.rs 
mehaničke osobine mišića. Njihov značaj ogleda se u tome što od njih u velikoj meri zavisi uspeh u svim oblastima gde je pokret dominantan. Mehaničke osobine mišića se mogu opisati i relacijom sile i brzine, sile i dužine i sile i vremena [2]. Odnos između sile i brzine (F-V relacija) predstavlja novu tendenciju u testiranju, metodu koja omogućava istovremenu procenu osnovnih mehaničkih osobina mišića [3, 4]. Ova metoda je u direktnoj vezi sa biomehaničkom dijagnostikom jer se njihovom zajedničkom upotrebom dolazi do saznanja o svojstvima čovekovog mišićnog sistema. Biomehaničkom dijagnostikom se mogu direktno (dinamometrija, tenziometrija, kinematika) i indirektno (linearna F-V relacija) proceniti mehaničke osobine mišića. Direktna procena mehaničkih osobina mišića je učestalija u praksi. Međutim, da bi se procenila maksimalna sila, brzina i snaga direktnim putem potrebno je sprovesti veći broj testova nakon čega dobijeni nalazi neće biti procenjeni u jednakim mehaničkim uslovima [5]. Zbog pomenutih nedostataka, nauka ide u smeru indirektnog procenjivanja mehaničkih osobina mišića, gde se biomehanička dijagnostika koristi zajedno sa linearnom F-V relacijom.

Sa razvojem nauke i tehnologije procena mehaničkih osobina mišića je unapređena, dobijeni nalazi su precizniji, a procedure testiranja jednostavnije. Postoje raznovrsne metode koje su zamenile testiranja uz pomoć „štapa i kanapa” i koje omogućuju bolju biomehaničku dijagnostiku. U savremenoj sportskoj i medicinskoj literaturi najčešće korišćene metode su dinamometrijska, tenziometrijska i kinematička metoda. $U$ vezi sa tim često korišćena tehnologija u primeni navedenih metoda podrazumeva: izokinetičke dinamometre, tenziometrijske platforme i kamere za trodimenzionalnu (3D) kinematičku analizu pokreta. Pomenute metode, odnosno tehnologije, omogućuju snimanje, beleženje i analizu kinetičkih i kinematičkih parametara kod jednozglobnih i višezglobnih pokreta. Poznavanje pomenutih parametara kod višezglobnih pokreta je od velikog značaja jer oni opisuju svakodnevno čovekovo kretanje i sportske aktivnosti.

Glavni cilj ove studije jeste analiza metoda biomehaničke dijagnostike koji se mogu koristiti u proceni mehaničkih osobina mišića. Procena mehaničkih osobina mišića je od velikog značaja za sport i medicinu jer se samo na osnovu njihovog poznavanja može saznati njihovo trenutno stanje, uočiti napredak i izvršiti poređenje sa drugim rezultatima.

\section{METODE}

Za potrebe ove studije korišćen je bibliografsko-deskriptivni metod. Pretraga literature sprovedena uz pomoć sledećih servisa: PubMed, Google, Google Schoolar i Kobson. Ključne reči za traženje odgovarajuće literature bile su: mehaničke osobine mišića, biomehanička dijagnostika, mehanička svojstva mišića, informacione tehnologije u sportu, kinematička analiza, kinetička analiza, analiza pokreta, izokinetički dinamometar, kamere za 3 D analizu pokreta, tenziometrijska platforma.

\section{REZULTATI I DISKUSIJA}

$\mathrm{Na}$ osnovu pregleda literature, u nastavku rada biće posebno analizirana svaka od metoda biomehaničke dijagnostike. Metode će, pre svega, biti predstavljene kroz analizu tehnologije koja prati svaku od metoda. Uz to biće analiziran i način procene najznačajnijih mehaničkih osobina mišića u zavisnosti od primenjene metode.

\section{Izokinetički dinamometar (dinamometrijska metoda)}

Primena dinamometrijske metode korišćenjem izokinetičkog dinamometra u sportu, kliničkim testiranjima i istraživanjima datira još od 1960. godine [6]. Osnovna karakteristika izokinetičkog dinamometra je konstana ugaona brzina koju segment tela savladava prilikom izvođenja jednozglobnog pokreta. Izokinetičkim dinamometrom može se proceniti sila i snaga mišića u koncentričnoj i ekscentričnoj kontrakciji. Takođe, procena maksimalne sile i snage je moguća i u izometrijskim uslovima. Na izokinetičkom dinametru se najčešće procenjuju maksimalna sila (Maximal force - Fmax) i brzina razvoja sile (Rate of force development - RFD). Maksimalna sila se definiše kao sposobnost da se generiše maksimalno moguće ispoljavanje sile određenog mišića ili mišićne grupe. Sa druge strane, RFD predstavlja sposobnost mišića da velikom brzinom razvije što je moguće veću silu. RFD u velikoj meri pokazuje eksplozivne sposobnosti mišića, tačnije njegove neuralne komponente [7]. Procena RFD je često važnija za testiranje kod sportista nego procena sile. Jedan od razloga za to je što se u većini sportova izvode brze kretnje koje zahtevaju brzo generisanje određenog nivoa sile, ali ne i dostizanje maksimalne sile.

Testiranja na izokinetičkom dinamometru se izvode u jednom zglobu, odnosno tzv. otvorenom kinetičkom lancu. Direktno procenjivanje sile i snage moguće je kod 
mišića nogu, ruku i ramenog pojasa, trupa i leđa, a to se sve postiže uz pomoć posebnih nastavaka iz standardizovanih početnih pozicija (Slika 1). Posebnim trakama vrši se fiksacija delova tela, kako bi se izolovala mišićna grupa koja se testira.

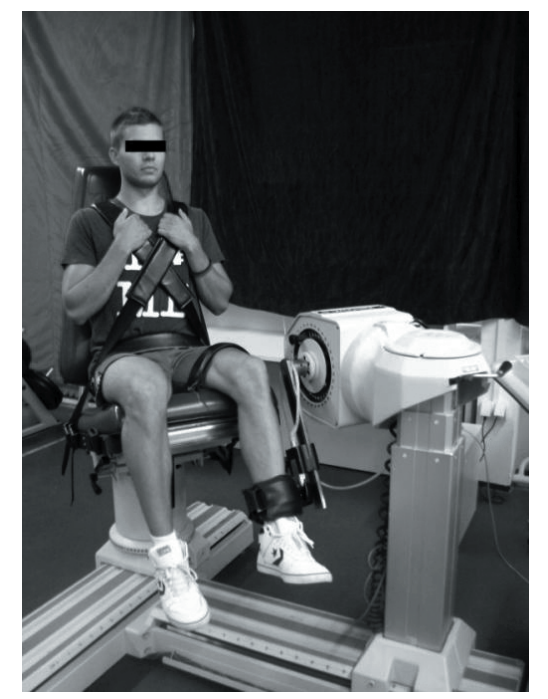

Slika 1. Testiranje na izokinetičkom dinamometru u zglobu kolena

Preciznost dobijenih nalaza kod ove tehnologije zavisi od opsega izvođenja pokreta, odnosno on je u direktnoj vezi sa momentom sile [6]. Iz tog razloga je veoma bitno zabeležiti opseg izvođenja pokreta prilikom svakog testiranja na izokinetičkom dinamometru. Veoma snažni ispitanici prilikom testiranja mogu dovesti do pomeranja aparature, a samim tim i promene ugla u zglobu, što može uticati na rezultate testiranja.

Prednost ove tehnologije ogleda se u boljoj kontroli uslova merenja, koja se postiže kontrolom brzine merenja. Takođe, preko izokinetičkog dinamometra se jednostavno procenjuju osnovne mehaničke osobine mišića. Izokinetički dinamometar poseduje sondu koja registruje promenu sile u jedinici vremena. $\mathrm{S}$ obzirom na to da je u izokinetičkom režimu rada brzina konstantna, onda se i snaga računa vrlo jednostavno (kao proizvod sile i brzine). Međutim, procena sile, brzine i snage na ovaj način dobija se u uslovima koji ne reprezentuju svakodnevne čovekove aktivnosti (dinamički režim rada mišića, odnosno povezivanje koncentrične i ekscentrične kontrakcije). Takođe, izokinetički dinamometar se koristi isključivo za laboratorijska testiranja jer zbog gabarita njegova primena u terenskim uslovima nije moguća.
Tenziometrijska platforma (tenziometrijska metoda)

Primena tenziometrijske metode je veoma rasprostranjena u različitim oblastima, pa je pored sportskih institucija često primenjuju i medicinske ustanove. Analiza hoda, trčanja, skokova su samo neke od mogućnosti koje se prate kod različitih populacija i uzrasta. Takođe, procena sile preko tenziometrijske metode korišćenjem tenziometrijske platforme može omogućiti kvantitativno ocenjivanje mehaničkih osobina mišića. Većina tenziometrijskih platformi mogu istovremeno proceniti spoljne sile reakcije podloge po frontalnoj, sagitalnoj i tranferzalnoj osi (Slika 2).

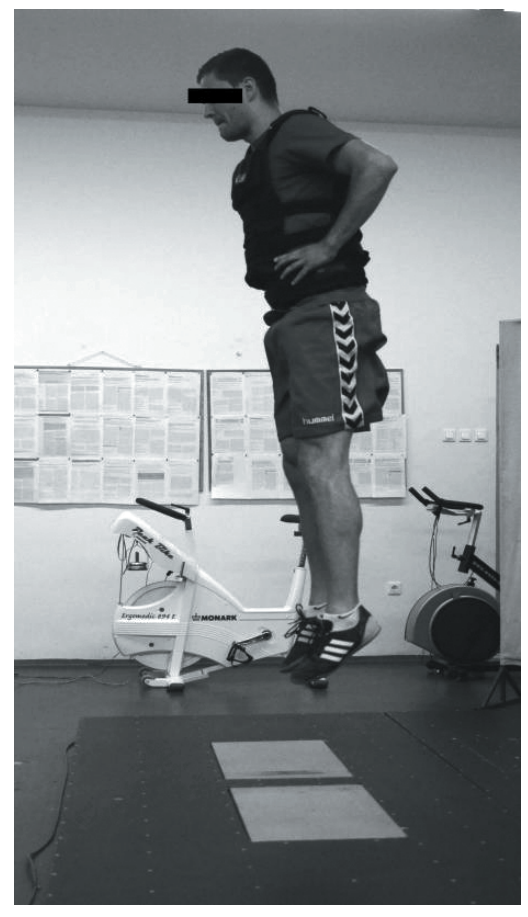

Slika 2. Testiranje skoka uvis na tenziometrijskim platformama.

U sportu se najčešće koristi vertikalna komponenta sile reakcije podloge, i to, pre svega, u testiranju skokova uvis. Tom prilikom se procenjuje eksplozivna snaga mišića opružača nogu. Registrovanje sile reakcije podloge se obavlja pomoću preciznih senzora visoke frekvencije (1000 do $2000 \mathrm{~Hz}$ ). Na Slici 3 prikazan je signal sile reakcije podloge od početka delovanja sile na platformi, do dobijanja digitalnog signala. 


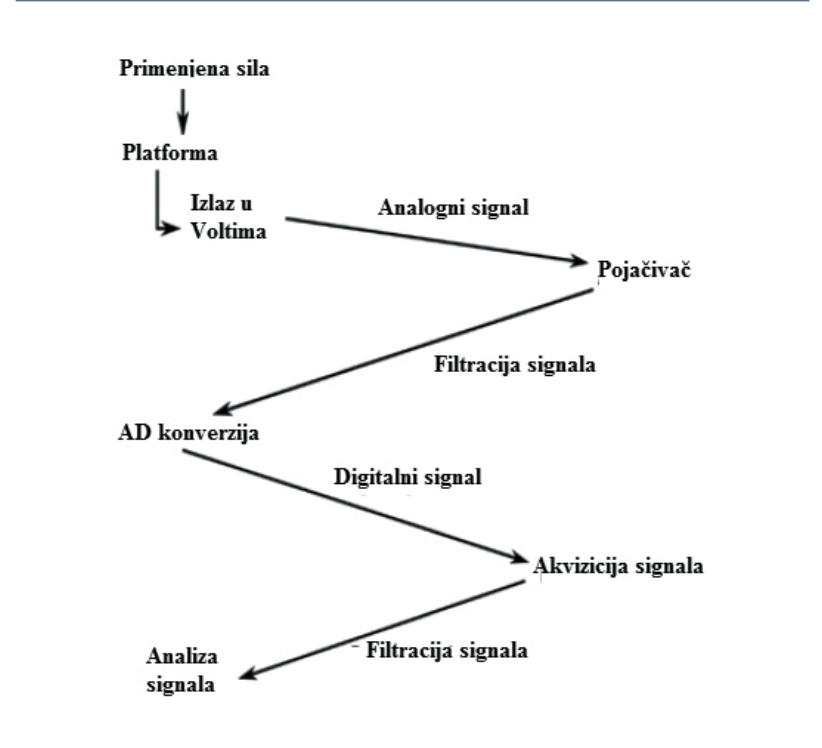

Slika 3. Šematski prikaz kretanja signala sile reakcije podloge [8].

Dobijeni digitalni signal podrazumeva silu u jedinici vremena. Kasnijom obradom signala, primenom nekog od softverskih paketa (MatLab ili LabView) signal se propušta kroz niskopropusni rekurzivni filter drugog reda (Butterworth, frekvencija sečenja $10 \mathrm{~Hz}$ ), a brzina i pozicija centra mase izračunavaju se kroz postepenu integraciju ubrzanja dobijenog iz signala sile. Filtirani signal se nakon toga koristi za izračunavanje sile i brzine iz koncentrične ili ekscentrične faze (Slika 4).
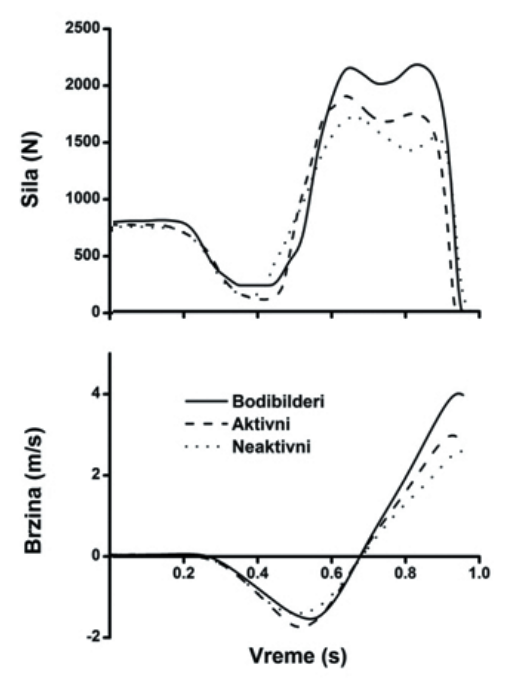

Slika 4. Zapis signala sile i brzine dobijenih na tenziometrijskoj platformi [9].

Proizvodom sile i brzine dobijamo još jednu značajnu mehaničku osobinu mišića, a to je snaga.

\section{Kamere za 3D kinematičku analizu pokreta}

Kinematičkom metodom, uz pomoć kamera za 3D kinematički analizu pokreta (Slika 5), najčešće se procenjuju kinematički parametri ljudskog kretanja (brzina i ubrzanje segmenata tela ili celog tela, uglovi u određenim zglobovima, pređeni put i dr.) Putem kinematičke analize pokreta mogu se proceniti i mehaničke osobine mišića. Minimalni broj potrebnih kamera za analizu translatornih kretanja je tri, dok je za analizu rotacionih kretanja potrebno minimum šest kamera.

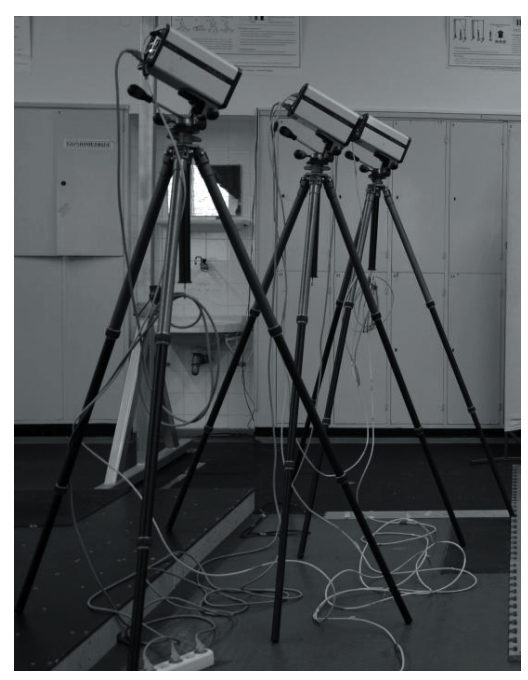

Slika 5. Kamere za 3D kinematičku analizu pokreta.

Nakon sinhornizacije i kalibracije kamera sa realnim prostorom, ovom metodom se mogu pratiti kretanja kako segmenata tela sportista, tako i kretanje celog tela. Tom prilikom se koriste reflektujući markeri koji se postavljaju na centre zglobova, čime se kreira često korišćen Dempsterov segmentalni model tela [10] koji se prilikom snimanja prebacuje u digitalni zapis (Slika 6).

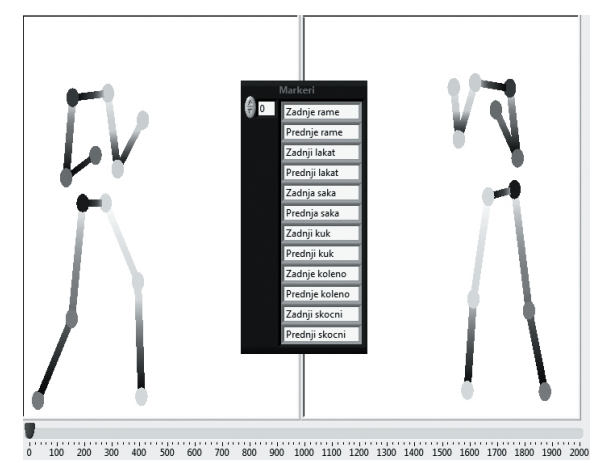

Slika 6. Digitalni zapis reflektujućih markera postavljenih na centre zglobova na primeru borbe $\mathrm{u}$ karateu 
Dobijeni signal predstavlja pređeni put nekog segmenta tela ili celog tela u jedinici vremena. Zatim, metodom inverzne dinamike (u nekom od softverskih paketa, poput LabView-a) mogu se izračunati i ostale mehaničke osobine mišića, poput sile (preko ubrzanja), ili snage (kao proizvoda sile i brzine). Velika prednost kamera za 3D kinematičku analizu je to što su mobilne i mogu se koristiti za terenska testiranja, što nije slučaj sa tenziometrijskim platformama i izokinetičkim dinamometrom.

\section{ZAKLJUČAK}

Razvoj nauke i tehnologije u znatnoj meri doprinosi unapređenju sporta i medicinskih nauka. Savremene informacione tehnologije danas predstavljaju neraskidivu vezu sa biomehaničkom analizom pokreta. Poznavanje kinetičkih i kinematičkih parametara, mehaničkih osobina mišića stiče se preciznija motorička slika i uvid u funkcionisanje čovekovog lokomotornog aparata.

U glavnom delu rada analizirane su tri najčešće metode biomehaničke dijagnostike, kao i tehnologije koje se primenjuju u tim metodama. Bez obzira na to koju tehnologiju odabrali i primenili mehaničke osobine mišića (sila, brzina i snaga) mogu se direktno proceniti u približno situacionim uslovima. Međutim, u praksi se njihovo procenjivanje često odvija u nejednakim mehaničkim uslovima. Procena mehaničkih osobina mišića može se sprovesti i istovremeno, ali se ona zasniva na upotrebi indirektne metode, odnosno korišćenja linearne F-V relacije. Primenom jednog testa i različitih intenziteta opterećenja, a na osnovu standardnog regresionog modela mogu se odrediti parametri maksimalne sile, brzine i snage. Ova indirektna metoda zajedno sa tehnologijama koje se primenjuju za biomehaničku dijagnostiku nadomešćuje gorepomenute nedostatke i predstavlja novu tendenciju u testiranju mehaničkih osobina mišića sportista, rekovalescenata, dece i starih osoba.

\section{LITERATURA}

[1] V. Zatsiorsky, The Encyclopaedia of Sports Medicine: An IOC Medical Commission Publication, Biomechanics in Sport: Performance Enhancement and Injury Prevention: John Wiley \& Sons, 2008.

[2] T. A. McMahon, Muscles, reflexes, and locomotion: Princeton University Press, 1984.

[3] S. Jaric, "Force-velocity Relationship of Muscles Performing Multi-joint Maximum Performance Tasks," International Journal of Sports Medicine, vol. 36, no. 9, pp. 699-704, 2015.

[4] M. Zivkovic, S. Djuric, I. Cuk, D. Suzovic, and S. Jaric, „Muscle force-velocity relationships observed in four different functional tests, "Journal of Human Kinetics, vol. 56, no. 1, pp. 39-49, 2017.

[5] S. Jaric, "Two-load method for distinguishing between muscle force, velocity, and power-producing capacities," Sports Medicine, vol. 46, no. 11, pp. 1585-1589, 2016.

[6] P. J. Maud and C. Foster, Physiological assessment of human fitness: Human Kinetics, 2006.

[7] P. Aagaard, EB. Simonsen, JL. Andersen, P. Magnusson, and P. Dyhre-Poulsen, "Increased rate of force development and neural drive of human skeletal muscle following resistance training," Journal of Applied Physiology, vol. 93, pp. 1318-1326, 2002.

[8] G. Beckham, T. Suchomel, and S. Mizuguchi, "Force plate use in performance monitoring and sport science testing," New Study Athletics, vol. 29, pp. 25 37, 2014.

[9] I. Cuk, DM. Mirkov, A. Nedeljkovic, D, Ugarkovic, M. Kukolj, and S. Jaric, "Force-velocity property of leg muscles in individuals of different level of physical fitness," Sports Biomechanics, vol. 12, no. 2, pp. 207-219, 2016.

[10] WT. Dempster and GR Gaughran, "Properties of body segments based on size and weight," Developmental Dynamics, vol. 120, no. 1, pp. 33-54, 1967. 